\title{
A COORDENAÇÃO PEDAGÓGICA COMO ESPAÇO DE FORMAÇÃO CONTINUADA DE PROFESSORES DOS ANOS INICIAIS NO CONTEXTO DO ENSINO DE CIÊNCIAS
}

\author{
Maria Eduarda Peres Oliveira ${ }^{1}$ \\ Delano Moody Simões da Silva²
}

\begin{abstract}
RESUMO
O presente trabalho tem como objetivo analisar uma experiência de formação continuada de professores dos anos iniciais, tendo como foco o ensino de ciências por investigação. Foram propostas atividades formativas (leituras e discussões, entre outras atividades) durante a coordenação pedagógica da escola, momento destinado para planejamento e estudo das professoras dos Anos Iniciais. As atividades eram discutidas, organizadas e, posteriormente, praticadas em sala de aula com os alunos e depois discutidas com o grupo para ser preparada uma nova sequência. Os resultados mostram que as atividades realizadas nas coordenações pedagógicas da escola em questão proporcionaram às professoras e à pesquisadora excelentes momentos de aprendizagem e reflexão sobre a prática docente, possibilitando que as docentes insiram mais conteúdos de ciências nos seus planejamentos e que a abordagem destes tenha uma perspectiva mais investigativa. A abordagem possibilitava não somente um maior engajamento dos alunos, mas também o desenvolvimento de outras habilidades, como a argumentação, o registro e a comunicação, dentre outros.
\end{abstract}

Palavras-chave: Formação docente. Ensino de ciências. Coordenação pedagógica.

\section{TEACHERS' MEETING AS A SPACE FOR CONTINUING TEACHER TRAINING} OF THE EARLY YEARS IN THE CONTEXT OF SCIENCE TEACHING

\begin{abstract}
The present work aims to analyze an experience of continued training of teachers of the early years focusing on the teaching of science through research. Formative activities were proposed (readings, discussions among other activities) during the teachers' meeting of the school, a moment destined for the planning and study of the teachers of the early years. The activities were discussed, organized and later practiced in the classroom with the students and then discussed with the group to prepare a new sequence. The results show that the activities carried out in the teachers' meeting of the school in question provided the teachers and the researcher with excellent moments of learning and reflection on the teaching practice, enabling the teachers to insert more contents of science in their planning and that the approach of these has a more investigative perspective. The investigative approach allows not only a greater engagement of students but allows the development of other skills such as argumentation, registration, communication among others.
\end{abstract}

Keywords: Teacher training. Science teaching. Teachers' meeting.

Recebido em: 26/8/2019

Aceito em: 29/9/2019

\footnotetext{
${ }^{1}$ Especialização em Gestão e Orientação Educacional pela Faculdade do Meio Ambiente e Tecnologia de Negócios (2014). Professor da Educação Básica da Secretaria de Educação do Distrito Federal. http://lattes.cnpq.br/3124237421237764. https://orcid.org/0000-00015201-8681. meduardaunb@gmail.com

2 Doutorado em Ecologia pela Universidade de Brasília (2006). Professor-associado da Universidade de Brasília. Tem como áreas de interesse formação de professores de ciências, ensino de ciências e recursos didáticos. http://lattes.cnpq.br/6137177500175585. https://orcid. org/0000-0002-6784-6161. delanomoody@gmail.com
} 
No Brasil, a Educação Básica é dividida em três níveis, a saber: Educação Infantil, Ensino Fundamental e Ensino Médio, com o Ensino Fundamental estando dividido em Anos Iniciais e Finais (BRASIL, 1996). Os Anos Iniciais abrangem do 10 ao 5o ano, com alunos na faixa etária de 5 a 11 anos de idade, tendo como objetivo a formação básica da criança por meio da alfabetização, raciocínio lógico matemático, formação de atitudes e valores, compreensão do meio ambiente, da ciência, arte, cultura, economia e tecnologia como parte integradora de seu pleno desenvolvimento, ressaltando as relações interpessoais da vida humana (BRASIL, 1996; DISTRITO FEDERAL, 2013).

Segundo a Lei de Diretrizes e Bases da Educação Nacional - LDB (BRASIL, 1996), os profissionais de educação que irão atuar na Educação Básica necessitam da formação em nível superior, Licenciatura Plena, e para a Educação Infantil e os Anos Iniciais a Licenciatura deve ser em Pedagogia, admitindo-se também o Magistério na modalidade normal (BRASIL, 2006). Dessa forma, cabe ao pedagogo, preferencialmente, a docência nos Anos Iniciais de escolarização.

A formação inicial do pedagogo deve proporcionar a esse profissional saberes comuns aos demais docentes por exemplo, as teorias de aprendizagem e didática, mas também saberes específicos de disciplinas como Língua Portuguesa e Matemática, o conhecimento do mundo físico e natural e da realidade social e política (BRASIL, 2006). Essas demandas de formação previstas na LDB (BRASIL, 1996) foram ratificadas recentemente na Base Nacional Comum Curricular - BNCC (BRASIL, 2017).

Dessa forma, há de se ponderar se a formação inicial do pedagogo lhe permitirá promover o pleno desenvolvimento de estudantes, uma vez que o ensino nos Anos Iniciais é caracterizado por sua complexidade e dificuldade de integrar vários tipos de saberes (LIMA; MAUÉS, 2006). Nesse sentido, Goldschmidt (2012, p. 36-37) afirma que "seria necessária uma formação específica para dominar conteúdos específicos; a formação geral do professor desse nível o impede de trabalhar com segurança". Silva (2005, p. 33), ao relatar sua experiência na formação em Pedagogia, reconhece essa fragilidade na formação em ciências, pois segundo os alunos "... não preparava de forma satisfatória para o ensino teórico e prático na área de Ciências."

Nesse sentido, devido à natureza multifacetada da formação do pedagogo é possível que apenas a formação inicial não seja capaz de promover o aprendizado dos alunos dos anos iniciais em áreas tão diversas como Português, Matemática, Ciências, entre outras. Sendo assim, a formação continuada para o pedagogo não é apenas uma alternativa, mas uma demanda para aprimorar o exercício de sua profissão.

A formação continuada, no entanto, não deve se limitar a atualizar os professores com novas informações ou "ensinar novos truques" (LIMA; MAUÉS, 2006; SCHNETZLER, 2003), mas deve, respeitando a autonomia dos docentes (ALARCÃO, 2011; ZEICHNER, 1993), sua história de vida e seus saberes (NÓVOA, 2007; TARDIF, 2014), e reconhecendo a escola como espaço de formação (MALDANER, 2006), promover estudos e reflexões sobre a prática docente.

As atividades de formação que ocorrem no próprio espaço escolar possibilitam momentos de aprendizagem individual, assim como momentos de trabalho coletivo e colaborativo entre colegas têm seus efeitos ampliados (DARLING-HAMMOND et al., 2009; JOHNSON, 2009). Para Stosich (2016), os encontros de professores (teachers' 
meeting, em inglês), que correspondem aos momentos de coordenação pedagógicos aqui no Brasil, são os espaços adequados para esse trabalho colaborativo, pois como afirma Nóvoa (1992, p. 26), o "diálogo entre professores é fundamental para consolidar os saberes emergentes na prática profissional".

Nesse sentido, os espaços de coordenação pedagógica e planejamento são importantes para o preparo do trabalho do docente, nos quais pode ser desenvolvida a articulação entre as dimensões do ensino-aprendizagem, pesquisa e avaliação. Ressalta-se que estes também devem ser um ambiente destinado à formação continuada do professor (SILVA, 2007).

Dessa forma, entendendo o papel fundamental da formação continuada para os professores dos anos iniciais e que os seus efeitos podem ser potencializados quando ocorre no próprio ambiente escolar, o presente trabalho apresenta a análise de uma experiência de formação continuada de professores dos anos iniciais baseada no ensino de ciências por investigação realizada em uma escola pública do Distrito Federal.

\section{FORMAÇÃO CONTINUADA E A COORDENAÇÃO PEDAGÓGICA}

A formação continuada de professores assume um papel importante na educação, pois dá sequência aos estudos iniciais dos cursos de Graduação, agregando conhecimento e somando valores à prática pedagógica em sala de aula (FERNANDES, 2007). Dessa forma, o professor deve permanecer em constante formação para estar a par dos conhecimentos, reflexões e planejamentos a serem providos aos seus alunos, levando a uma melhoria do sistema educacional (SILVA, 2007).

Os processos de formação continuada não irão somente contribuir para a qualidade das ações do docente (BASTOS, 2014), mas irão renovar, consolidar e ampliar saberes culturais e científicos desses sujeitos, além de contribuir para a construção da identidade do professor (PORTO, 2000; FERNANDES, 2007).

Imbernón (2010) destaca vários aspectos que devem ser levados em consideração nos processos formativos de professores em exercício, mas três deles merecem destaque, pois dialogam com a proposta deste trabalho. O primeiro, já indicado anteriormente, é o cuidado com a visão simplista de que para formar professores em exercício basta "transmitir" novos conhecimentos ou métodos. O segundo destaca a importância do trabalho em equipe, denominado pelo autor como "colegialidade". E por fim a necessidade de que esse processo formativo ocorra de dentro para fora, ou seja, ele deve partir da realidade e demandas da comunidade escolar e não trazido por pessoas/profissionais fora daquele contexto.

Na mesma perspectiva, Nóvoa (2007) defende que a formação deve ocorrer no espaço escolar, pois a partir de fatos reais e concretos, as ações podem ser pensadas e praticadas visando a sanar e superar as dificuldades de determinado contexto. A colaboração e o engajamento dos professores nesse processo não só melhoram a qualidade da formação, como também criam um melhor ambiente de aprendizagem para os alunos (RONFELDT et al., 2015).

Tal ambiente de formação é previsto na rede pública do Distrito Federal e é denominado como "Coordenação Pedagógica", o qual foi resultado de diversas lutas conquistadas pelos professores, sob a argumentação de que a existência de um momento 
destinado aos estudos subsequentes contribuiria para a melhoria da educação (DISTRITO FEDERAL, 2013 ), sendo descrita como espaço e tempo de trabalho coletivo, dinâmico e reflexivo, no qual todos os professores são protagonistas na constituição de suas práticas, em que se consiga abarcar todas as necessidades e delimitações dos alunos. Dessa forma, no Distrito Federal, a Coordenação Pedagógica é o momento em que os professores, sob a supervisão de um coordenador pedagógico, irão planejar e discutir suas ações em sala de aula, caracterizando-se não só como uma reunião de trabalho, mas um momento de estudo e aprofundamento da prática docente.

Somente a existência da coordenação pedagógica, porém, não garante que esta cumpra com o objetivo de formação. É necessário que se constitua um grupo de professores com objetivos em comum, que compartilhem os contextos e dificuldades do ambiente de trabalho (CRESPO, 2006), que esse seja um espaço de investigação e troca de vivências entre professores, de forma que apoiem e sustentem as mudanças que ocorrerão na escola (MUNFORD; LIMA, 2007). Lima e Santos (2007) ressaltam ainda que a coordenação pedagógica não deve se caracterizar como um espaço mecânico ou burocrático, mas sim um espaço de diálogo entre pares que contribui para o fortalecimento do grupo e de melhoria da qualidade do ensino e da aprendizagem no ambiente escolar (BASTOS, 2014).

Para que a coordenação pedagógica seja esse espaço de dialogicidade, porém, é necessário a figura do coordenador pedagógico como sendo o mediador de todo o trabalho desenvolvido, valorizando as ações coletivas e articulando os diferentes segmentos da comunidade escolar (ALARCÃO, 1996; LIMA; SANTOS, 2007). Vasconcellos (2004) lembra que o coordenador pedagógico é, antes de tudo, um professor naquele contexto, escolhido para desempenhar a função de mediar os processos formativos, e que pode ser auxiliado em determinado momento por outros professores do grupo.

Dessa forma, a Coordenação Pedagógica assume um papel de grande importância no contexto escolar e na formação continuada de professores ao tornar-se um espaço de reflexão, no qual o professor escuta, debate e pensa situações de sua prática pedagógica, e por possibilitar um ambiente destinado aos estudos que visam à melhoria do trabalho em sala de aula e na escola como um todo.

\section{O ENSINO DE CIÊNCIAS NOS ANOS INICIAIS}

Ao ensinar ciências para seus alunos, o professor colabora para a compreensão de mundo do estudante, permitindo que ele se reconheça como parte integrante e participativa do ambiente, que ele compreenda, explique e intervenha no mundo em que vive (BRASIL, 2017; VIECHENESKI; CARLETTO, 2016). Na percepção de Bizzo (1998, p. 14), o ensino de Ciências deve despertar nos alunos excitação perante o desconhecido, promovendo a busca por elucidações lógicas e razoáveis, validadas em subsídios tangíveis. Além disso, deve promover a alfabetização científica por meio de práticas sociais que envolvam a ciência (KRASILCHIK; MARANDINO, 2004).

Atender às demandas citadas é uma tarefa desafiadora, que devido à formação generalista do professor dos Anos Iniciais, podem não ser disponibilizadas nessa etapa de escolarização (VIVEIRO; ZANCUL, 2013). Pimenta et al. (2017), ao realizarem um estudo em diferentes cursos de Pedagogia, observam que a maioria dos cursos consegue 
formar um professor polivalente, justamente pela diversidade de saberes que deveriam estar presentes nessa formação, mas não atende à formação de conteúdos específicos como Ciências, corroborando o indicado por Gabini e Diniz (2012).

No ensino de ciências os alunos devem ser estimulados a reelaborar e revisitar teorias científicas, aproximando esse conhecimento da sua realidade, descobrindo os significados do mundo, de forma a pensar, agir, refletir, criar opiniões e serem críticos de suas pressuposições (SILVA, 2005). Entre as possíveis abordagens das ciências para alcançar esses objetivos, o Ensino de Ciências por Investigação (Enci) é uma das alternativas mais completas, pois permite que os alunos interajam, explorem e experimentem o mundo natural, mas não fiquem jogados à própria sorte, nem restritos à manipulação ativista e meramente lúdica (SASSERON; CARVALHO, 2011; CARVALHO, 2013). Uma abordagem baseada na proposição de situações-problema, orientadas e acompanhadas pelo professor durante todo o processo de investigação, proporciona aos alunos a construção de novos conhecimentos do que está sendo investigado (LIMA; MAUÉS, 2006).

Ensinar ciência numa perspectiva investigativa vai além dos conteúdos tradicionais, pois promove uma maior autonomia nos alunos, propiciando uma mudança na tradicional relação professor-aluno (ANDERSON, 2007). Além disso, na abordagem investigativa o professor possibilita que os estudantes conheçam a cultura científica (SASSERON, 2008) e se tornem mais capazes de interagir e compreender temas e situações do dia a dia (SASSERON; CARVALHO, 2011).

A presença do Enci em nossas salas de aula, no entanto, ainda é muito limitada (ZÔMPERO; LABURÚ, 2011; COLOMBO JUNIOR et al., 2012; TRIVELATO; TONIDANDEL, 2015), sendo a formação, ou a falta dela, a principal barreira para uma abordagem mais investigativa em sala de aula (GODOY; SEGRRA; MAURO, 2014; SANTANA; FRANZOLIN, 2018). O professor que não teve a investigação ou pesquisa como princípio formativo em algum momento de sua formação inicial, terá certamente dificuldades em utilizar a investigação tanto como estratégia de ensino ou como conteúdo de aprendizagem (BYBEE, 2000).

Sendo assim, possibilitar que as professoras conheçam ou aprofundem seus conhecimentos sobre Enci durante as coordenações pedagógicas o fortalece como um espaço de formação continuada dentro da escola, potencializando seus efeitos na prática docente das professoras participantes.

\section{METODOLOGIA}

\section{Contexto}

O presente trabalho foi realizado em uma escola do campo da rede pública do Distrito Federal, situada na cidade do Gama, no 10 semestre de 2018. A referida escola conta com quatro segmentos de ensino, sendo eles: Educação Infantil - pré-escola; Ensino Fundamental completo; Educação de Jovens e Adultos e Ensino Médio. Na escola, nove professoras lecionam nos Anos Iniciais do Ensino Fundamental, porém apenas sete concordaram em participar do estudo. 


\section{Delineamento Metodológico}

Este estudo é caracterizado como uma pesquisa qualitativa, pois apresenta um contato direto entre os dados e a pesquisadora, ou seja, a pesquisadora estava inserida no ambiente no qual o estudo foi realizado (LUDKE; ANDRÉ, 2015). Além disso, devido à característica de um grupo trabalhando de forma colaborativa com o objetivo de refletir sobre a prática docente e incorporar aspectos do ensino por investigação, este projeto constituiu-se uma pesquisa participante do tipo pesquisa-ação (TRIPP, 2005). Durante o período de realização do projeto a pesquisadora atuou como coordenadora pedagógica da escola em questão.

Antes de elaborar e executar as atividades formativas de ciências foi aplicado um questionário para subsidiar as ações, no qual buscou-se conhecer um pouco mais das professoras que iriam participar da proposta e suas concepções sobre a Coordenação Pedagógica. Segundo Gil (2008, p. 121), o questionário é uma técnica de investigação que permite obter informações sobre conhecimentos, crenças, sentimentos, valores, interesses, expectativas, etc. Caso fosse necessário, para esclarecimento de alguma resposta ou dúvida com as professoras, foi marcada uma conversa com as participantes individualmente. O questionário era composto por dez questões abertas, as quais abordavam desde a formação e tempo de docência, até o papel da Coordenação Pedagógica na concepção das professoras.

A partir desses dados iniciais foi elaborado um planejamento inicial com cinco encontros de formação em espaço promovido na Coordenação Pedagógica com duração de carca de duas horas para cada encontro. Foi feito um planejamento apenas do primeiro encontro, pois os demais dependeriam da demanda das próprias professoras. Sempre foi considerado que o objetivo dessas atividades não era ensinar ou instrumentar as professoras nas atividades de ciências, mas sim problematizar a própria prática docente e propor em conjunto ações de intervenção em sala de aula.

Os encontros foram planejados para ocorrerem quinzenalmente. Independentemente do tema do dia, estes possuíam estrutura semelhante a partir do segundo encontro, um momento de discussão inicial, retomando o que foi discutido no encontro anterior, a atividade proposta para o dia e o planejamento para realização de atividades em sala e o próximo tema de discussão.

\section{Construindo os Dados}

Como instrumentos de coleta de dados utilizamos o questionário inicial, o caderno de campo (utilizado durante os encontros) e as entrevistas narrativas.

A escolha do caderno de campo como um dos instrumentos de coleta foi baseada em Laville e Dionne (1999, p. 154), que afirmam que o pesquisador não pode tudo ver e ouvir "fixando o que lhe parece útil, bem como o que lhe parece negligenciável", fazendo-se necessário um local de registro e orientação. Dessa forma a pesquisadora utilizou um caderno de campo para seu registro de impressões, reflexões, informações, entre outros aspectos que achasse pertinente ao longo da intervenção. 
A entrevista narrativa foi escolhida conforme as fundamentações de Bauer e Gaskell (2002), pois proporciona ao entrevistado a exposição de determinada história ou situação a partir de acontecimentos relevantes em uma sequência lógica, sem a interrupção dos fatos descritos.

As entrevistas ocorreram em momentos preestabelecidos com os sujeitos pesquisados nos tempos destinados à Coordenação Pedagógica da escola. Uma professora por vez foi entrevistada e suas respostas foram gravadas e posteriormente transcritas, servindo de dados para o trabalho. Além das professoras o diretor da escola também foi convidado a participar de uma entrevista abordando a sua percepção sobre o processo formativo das professoras. Para este trabalho as professoras serão identificadas por letras do alfabeto (ex.: Professora A) e o diretor apenas pelo cargo que ocupa.

Os dados coletados a partir do caderno de campo e das entrevistas narrativas foram analisados na perspectiva metodológica da análise de conteúdo (BARDIN, 2011). Essa metodologia permite analisar conteúdos de origem verbal e não verbal, focando nas vivências do sujeito e suas percepções sobre um objeto ou fenômeno (BARDIN, 2011). Inicialmente foi realizada uma leitura de todo o material oriundo das atividades e a partir desse primeiro contato foi possível agrupar as falas das professoras. Esses agrupamentos estavam relacionados a dois temas, as Coordenações Pedagógicas e o ensino de ciências nos Anos Iniciais. A partir desses agrupamentos procurou-se identificar aspectos que se destacassem em cada tema e foram encontradas duas categorias: Importância e Prática. Na categoria Importância as professoras reconhecem e indicam porque determinada temática é importante tanto no aspecto formativo delas como para sua prática docente. A categoria Prática está mais relacionada às ações das professoras, ao "fazer", seja nos momentos de coordenação ou nas atividades de sala de aula com os alunos.

\section{RESULTADOS E DISCUSSÃO}

\section{Investigação Inicial}

Na escola há nove professoras atuando nos anos iniciais, mas apenas sete concordaram em participar da pesquisa. Dessas, três são formadas em Pedagogia, duas em Geografia, uma em Matemática e uma em Letras, observando-se que as não formadas em Pedagogia possuem o curso de Magistério na modalidade normal, o que lhes permite atuar nos Anos Iniciais. Todas as professoras são formadas há mais de 10 anos e trabalham nessa escola há pelo menos 2 anos.

Sobre as Coordenações Pedagógicas, as professoras reconhecem a sua importância e citam a troca de experiências e a reflexão sobre a prática docente como aspectos significativos na coordenação:

A coordenação pedagógica é importante, pois serve de instrumento que ampara o seu trabalho em sala de aula (Professora A). 
É de fundamental importância, pois é por meio da coordenação pedagógica que há a troca de experiência, conhecimento, a reflexão da prática e até mesmo uma ressignificação da mesma. A coordenação é um espaço de problematização de reflexão (Professora B).

A percepção das professoras está de acordo com Fernandes (2007, p. 7), que indica que a coordenação é também um espaço de formação continuada para que os professores promovam avanços e reflexões sobre prática docente. Além disso as professoras indicam que:

As coordenações dão norte para o trabalho em sala de aula (Professora C).

É primordial, pois preciso confeccionar jogos, estudar sobre o assunto a trabalhar e elaborar as atividades a serem desenvolvidas (Professora D).

Dessa maneira, o momento de coordenação pedagógica torna-se válido, pois é um espaço para o planejamento e organização da prática pedagógica a ser realizada em sala de aula, além de ser um momento em que as professoras se encontram e podem trocar experiências e pensar em suas práticas como num ciclo do pensar - fazer - repensar (SCHÖN, 1992).

Quanto à Prática das coordenações, as professoras sinalizam que, de certa forma, as ações realizadas na coordenação já atendem a algumas de suas demandas:

Nos reunimos duas vezes na semana para os assuntos específicos de cada ano e um dia coletivamente para as demandas gerais da comunidade (Professora D).

Geralmente na busca de soluções características de cada turma (Professora B).

Pelas falas das professoras fica claro que as coordenações acontecem em grupos e buscam solucionar problemas específicos das turmas. Solucionar problemas ou atender a demandas específicas das turmas certamente está dentro dos objetivos da coordenação pedagógica, mas se este for o único foco da coordenação, pode acarretar uma segmentação das ações das professoras, além de contribuir pouco para o processo formativo delas na escola. García e Marcelo (1998) afirmam que momentos de trabalho coletivo de professores proporcionam o autoaperfeiçoamento e reflexão pela possibilidade de interação, discussão e fomento de atividades, trocas de experiências e autoavaliação de seu trabalho pedagógico.

Ainda dentro da Prática nas coordenações, as professoras colocam-se como participantes ativas de todo o processo:

Sou parte do grupo. E é de grande importância a participação de cada um de nós na coordenação das atividades a serem desenvolvidas em sala e em todo âmbito escolar (Professora D).

Papel participativo, por meio das falas e dos cursos já realizados faço sugestões para melhoria da organização do trabalho pedagógico da escola (Professora G).

Deste modo é observado que as professoras sentem-se parte do coletivo e que as suas contribuições durante as coordenações são para a melhoria do trabalho pedagógico na escola e é por isso que a coordenação pedagógica é um espaço rico para o trabalho do professor, pois é nesse ambiente de troca e de discussão que surgem possibilidades de práticas pedagógicas que venham a auxiliar a aprendizagem do aluno. 


\section{Sobre os Encontros de Formação}

Como mencionado anteriormente, apenas o primeiro encontro foi planejado de forma detalhada e o objetivo dele era discutir a importância do Ensino de Ciências e da Alfabetização Científica nos anos iniciais (Quadro 1). Ao final de cada encontro o grupo decidia qual seria o tema abordado no encontro seguinte, ou seja, todas as temáticas foram decidas coletivamente. Como podemos observar no Quadro 1, os temas são assuntos presentes no currículo do DF (DISTRITO..., 2013), mas as professoras sinalizaram ter dificuldade com conceitos e/ou estratégias para abordá-los.

\section{Quadro 1 - Atividades Desenvolvidas na Coordenação Pedagógica com as Professoras Partici-} pantes da Pesquisa

\begin{tabular}{|c|c|c|c|}
\hline ENCONTRO & TEMA & OBJETIVO & METODOLOGIA \\
\hline 10 & $\begin{array}{l}\text { Ensino de } \\
\text { Ciências }\end{array}$ & $\begin{array}{l}\text { Discutir e ampliar os } \\
\text { conhecimentos sobre } \\
\text { Ensino de Ciências e } \\
\text { Alfabetização Científica. }\end{array}$ & $\begin{array}{l}\text { As professoras foram divididas em duplas e } \\
\text { receberam dois trechos de artigos referentes ao } \\
\text { Ensino de Ciências e Alfabetização Científica. Cada } \\
\text { dupla tinha } 15 \text { minutos para discutir sobre os trechos. } \\
\text { Após esse tempo cada dupla deveria ler para os } \\
\text { demais seus trechos e apresentar suas discussões. }\end{array}$ \\
\hline 2o & Água & $\begin{array}{l}\text { Integrar os } \\
\text { conhecimentos advindos } \\
\text { dos alunos ao campo } \\
\text { do Ensino de Ciências } \\
\text { com outras áreas do } \\
\text { conhecimento, como } \\
\text { Português, Geografia, } \\
\text { História e Artes, na } \\
\text { temática sobre Água. }\end{array}$ & $\begin{array}{l}\text { Inicialmente a discussão concentrou-se em Ciências: os } \\
\text { estados físicos da água, a mudança dos estados da água, } \\
\text { bem como a importância do uso sustentável da água. } \\
\text { Num segundo momento foi discutido o ensino da } \\
\text { Língua Portuguesa, no qual é possível incluir leitura e } \\
\text { análise de quadrinhos e reportagens. Juntamente com } \\
\text { as atividades de Artes foram produzidas histórias em } \\
\text { quadrinhos nos murais. } \\
\text { Durante a atividade foi discutido o uso da água nas } \\
\text { casas para o tratamento de esgoto, cisternas e fossas, } \\
\text { e o tema foi incluído nos componentes de História e } \\
\text { Geografia pelo fato de ser uma área rural, na qual onde } \\
\text { a maioria das casas utiliza poços artesianos e cisternas } \\
\text { para a captação da água para consumo diário. }\end{array}$ \\
\hline 3은 & Alimentação & $\begin{array}{l}\text { Estudar os alimentos e } \\
\text { a sua importância para } \\
\text { a nutrição humana de } \\
\text { modo a integrar ou } \\
\text { abordar o conteúdo } \\
\text { aos diversos campos do } \\
\text { ensino, como Ciências, } \\
\text { Matemática e Português. }\end{array}$ & $\begin{array}{l}\text { O ponto de partida para iniciar a sequência didática } \\
\text { foi o cardápio do lanche ofertado pela escola. Sugeriu- } \\
\text { se que as professoras indagassem seus alunos com as } \\
\text { seguintes questões: I) Vocês gostam de comer o que } \\
\text { tem na escola? II) O que comem é saudável? III) Vocês } \\
\text { sabem o que é alimentação saudável? E abrir para } \\
\text { discussões mediadas pelo professor. } \\
\text { Em sequência sugeriu-se a leitura das refeições/ } \\
\text { alimentos disponíveis na dieta da escola. Após essa } \\
\text { leitura será possível subsidiar as temáticas de: I- } \\
\text { Importância dos alimentos; II - Pirâmide alimentar/ } \\
\text { grupos; III - Nutrientes/ grupos. } \\
\text { Após o estudo dos conteúdos supramencionados } \\
\text { é possível averiguar com os alunos as seguintes } \\
\text { questões: Como ocorre a digestão? Para onde vão os } \\
\text { alimentos? O que acontece com o alimento?, para, } \\
\text { posteriormente, adentrar ao conteúdo do Sistema } \\
\text { Digestório. Foi relacionado também o conteúdo sobre } \\
\text { a importância dos dentes na digestão (mastigação). } \\
\text { Para as aulas destinadas ao conteúdo de Matemática, } \\
\text { o professor poderá utilizar a construção de gráficos } \\
\text { dos alimentos consumidos no cardápio da escola. } \\
\text { Ainda em Matemática, o professor, junto com seus } \\
\text { alunos, poderá estudar as medidas, quantidades e } \\
\text { conversão dessas para produção de uma receita de } \\
\text { um prato/refeição. } \\
\text { Concomitantemente com a Matemática, o docente } \\
\text { pode estudar o gênero textual receita, com a leitura } \\
\text { das quantidades, escrita e siglas, abordando, assim, o } \\
\text { Português. }\end{array}$ \\
\hline
\end{tabular}




\begin{tabular}{|c|c|c|c|}
\hline 40 & Meio Ambiente & $\begin{array}{l}\text { Propor atividades que } \\
\text { exercitem a investigação, } \\
\text { opinião e exposição de } \\
\text { ideias diante do tópico } \\
\text { do meio ambiente. }\end{array}$ & $\begin{array}{l}\text { Proporcionar aos alunos uma visita aos arredores } \\
\text { da escola para que observem o meio onde estão } \\
\text { inseridos, identificando e recolhendo o lixo (garrafas } \\
\text { pets, embalagens, recipientes, etc.) que encontrarem } \\
\text { pelo caminho, para realizarem atividades com esses } \\
\text { materiais. } \\
\text { No ensino de Ciências abordar a poluição, o } \\
\text { desmatamento, a vegetação, a fauna e o tempo de } \\
\text { decomposição dos objetos encontrados. } \\
\text { Em Português criar propagandas sobre os produtos } \\
\text { encontrados e seu descarte adequado, além da } \\
\text { produção de poemas e história em quadrinhos } \\
\text { baseados na temática. } \\
\text { No ensino da Matemática utilizar os dados das } \\
\text { embalagens e produzir situações-problema } \\
\text { envolvendo valores e sistema monetário. Quantidade: } \\
\text { gramas, ml, kg, L. } \\
\text { Em Geografia estudar a modificação da paisagem pelo } \\
\text { homem e o aumento da população versus o aumento } \\
\text { do lixo. } \\
\text { Durante as aulas de Artes e a partir de materiais } \\
\text { recicláveis encontrados na escola e aqueles trazidos } \\
\text { de casa, os alunos poderão confeccionar objetos } \\
\text { recicláveis, como carrinhos, brinquedos, jogos, porta- } \\
\text { objetos, porta-maquiagens e cestas, entre outros, e } \\
\text { fazer uma apresentação para a escola com a temática } \\
\text { de Meio Ambiente e Sustentabilidade, mencionando } \\
\text { a importância de cuidar do nosso planeta Terra e } \\
\text { mostrar os objetos produzidos. }\end{array}$ \\
\hline 50 & Seres Vivos & $\begin{array}{l}\text { Relacionar os conteúdos } \\
\text { de Seres Vivos às demais } \\
\text { áreas do conhecimento }\end{array}$ & $\begin{array}{l}\text { A partir da visitação dos arredores da escola } \\
\text { questionar os alunos sobre: O que ao nosso redor está } \\
\text { vivo? Qual a diferença entre vivo e não vivo? } \\
\text { Os alunos devem registrar suas ideias por escrita ou } \\
\text { desenho. } \\
\text { A partir desses questionamentos estudar as } \\
\text { características e diferenças dos seres vivos e não vivos } \\
\text { e o ciclo da vida (nasce, cresce, reproduz e morre). } \\
\text { Em Português fazer lista de palavras com os nomes } \\
\text { dos animais, elencar as características e diferença } \\
\text { dos seres vivos e não vivos e utilizar o dicionário para } \\
\text { buscar o significado das palavras difíceis e escolhidas } \\
\text { pela professora, além de fazer frases com as palavras. }\end{array}$ \\
\hline
\end{tabular}

Fonte: Elaboração dos autores.

Os processos formativos baseados em demandas dos próprios professores possibilitam um maior engajamento deles nas atividades (RONFELDT et al., 2015). No mesmo sentido García e Marcelo (1998) afirmam que as atividades desenvolvidas nos encontros de professores devem emergir dos docentes, de suas próprias situações e interesses ligados à realidade da sala de aula.

Além disso, favorecem a continuidade do grupo e reforçam a sua identidade (POPP; GOLDMAN, 2016). Esse engajamento ficou evidente pelo auxílio das professoras durante as atividades e pelo interesse demonstrado pelos temas abordados. Todas as professoras foram assíduas e participaram ativamente das atividades propostas. Inclusive tivemos a participação do diretor em boa parte de nossos encontros.

À medida que os encontros da coordenação pedagógica foram avançando, as professoras puderam falar sobre suas práticas pedagógicas em sala de aula, suas dificuldades e fragilidades, tornando o momento rico em troca de experiências com apoio e sugestões de ações. Esse é um papel importante da coordenação pedagógica, pois ações que nascem no grupo são mais efetivas, conforme afirma Silva (2007, p. 2): “O 
processo de formação docente centrado na escola tem como pressuposto o fato de ser o professor quem melhor conhece a sua realidade com as problemáticas e questões que emergem no seu contexto de trabalho".

Outro ponto de destaque foi a participação da pesquisadora como coordenadora pedagógica dos encontros, pois o fato de conhecer as professoras, a realidade da escola e sua comunidade permitiu uma visão mais completa e próxima do grupo de docentes, possibilitando uma melhor organização e planejamento das atividades propostas, viabilizando a sua introdução em sala de aula. As dificuldades pedagógicas e administrativas encontradas ao longo do processo foram superadas devido a esse conhecimento e inserção no ambiente de trabalho, valorizando assim que o/a coordenador/a pedagógico/a deve ser um professor do grupo.

\section{Sobre as Atividades de Formação}

Desde o primeiro encontro identificou-se que as professoras sabiam e entendiam sobre a importância do Ensino de Ciências e da Alfabetização Científica, demonstrando identificação com a temática. Em vários momentos indicaram a importância de estudar ciências nos Anos Iniciais, como podemos constatar pelos trechos transcritos a seguir:

Estudar Ciências é importante para a vida do aluno, e a forma como nós professores colocamos interfere no interesse do aluno pela aula (Professora B).

Vejo que ensinar Ciências é muito importante para que o aluno entenda o seu papel no mundo, pois ela faz parte de tudo que vivemos (Professora C).

A visão das professoras está de acordo com o que já era proposto nos PCNs (BRASIL, 1997, p. 15), que destacam que o papel das Ciências Naturais "é o de colaborar para a compreensão do mundo e suas transformações, situando o homem como indivíduo participativo e parte integrante do Universo".

Algumas professoras sinalizaram uma percepção diferente sobre a atual abordagem dada para o ensino de Ciências, como podemos observar na sequência:

A ciência que eu estudei e que era colocada na minha época de escola era completamente tradicional, o aluno não entendia as Ciências como parte integrante de sua vida (Professora A).

Não enxergo mais como conteudista e livresco, algo a ser seguido com os passos preestabelecidos (Professora E).

Essa percepção de mudança é importante e também é um dos objetivos da formação continuada, pois mudanças em conceitos e abordagens nas Ciências ocorreram nos últimos anos e os professores precisam ter acesso a isso por intermédio de processos formativos.

Com isso as professoras percebem a importância de alfabetizar seus alunos não só em Português e Matemática, mas em Ciências também: 
Alfabetizar [em termos] científicos está desde os primeiros anos escolares, [e se] que pode perceber que não é só alfabetizar na matemática e português, mas alfabetizar o menino para o mundo, para entender que a ciência está em sua vida diária que você, alfabetizando ele cientificamente, ele entenderá o mundo que o rodeia e assim abrirá novos caminhos aos demais conhecimentos (Professora F).

O alfabetizar científico é algo que todos deveríamos já ter noção, pois é importante que o nosso aluno saiba e internalize isso com ele, porque é parte da sua vida entender o mundo. $O$ mundo é ciência (Professora A).

Os temas científicos podem ser de grande ajuda nessa fase de escolarização, pois os alunos vão precisar aprender a ler, escrever e "aprender" Ciências; eles podem aprender a ler e escrever com as Ciências (BRASIL, 1997).

No retorno do terceiro encontro as professoras já perceberam a importância de estudar sobre assuntos que elas irão abordar nas suas aulas:

É, eu acredito que também essa possibilidade de a gente poder aprofundar nosso conhecimento teórico acerca do tema que você trouxe de ciências, porque nas coordenações nós tivemos esse espaço de estudo mesmo, de aprofundar os teóricos e não deixar essa base ficar, digamos, esquecida (Professora C).

A gente precisa estar embasada bem teoricamente para a gente poder aplicar, e houve essa questão de trazer sugestões de autores, de temas, para a gente estar estudando (Professora D).

O reconhecimento das professoras e do próprio diretor do impacto das atividades formativas fica evidente nos trechos a seguir:

Se reciclar é sempre muito importante; você sempre volta à coerência de que é necessário introduzir melhor ciência e dar continuidade nesse ciclo (Professora B).

Achei muito válido porque a gente precisa ressignificar esses espaços de coordenações, e o estudo de Ciências, com o direcionamento que foi dado e o apoio para que as professoras levassem de fato para sala de aula essa disciplina de maneira mais coordenada e organizada, é de suma importância para o sucesso do nosso trabalho pedagógico na escola (Diretor).

As falas supramencionadas demonstram que a formação continuada é fundamental para que professores aprimorem sua prática e em conjunto encontrem soluções para os problemas do cotidiano escolar, que devido a sua complexidade, sua formação inicial, por melhor que tenha sido, não se mostrou suficiente para superar todos os desafios (FRANCO; GONÇALVES, 2013).

Com relação à prática das professoras, é possível identificar que algumas propunham um ensino de Ciências mais amplo e de acordo com as perspectivas atuais, como o exemplo a seguir:

Diante da minha prática percebi que sem saber eu consigo relacionar as Ciências com as demais matérias do ensino, mas que sempre busco um Ensino de Ciências que priorizasse não a formação de cientistas, mas sim de alunos capazes de interferir em seu ambiente (Professora B). 
Ao final do primeiro encontro as professoras solicitaram que trouxéssemos uma proposta de aula como exemplo para elas compreenderem de que maneira poderíamos trabalhar Ciências numa perspectiva investigativa. Ao apresentarmos nossa proposta elas rapidamente sugeriam adaptações para inserir em aulas que elas já faziam ou estavam planejando fazer, como podemos observar:

Irei integrar o que foi proposto no roteiro de aula ao que eu já sei (Professora F).

Achei muito válido essa organização feita (roteiro didático), pois, assim, eu consigo visualizar melhor e saber que é possível relacionar o Ensino de Ciências às outras matérias (Professora A).

As falas das docentes, portanto, referem-se ao momento de discussão, análise e planejamento do que se pode aplicar em sala de aula. É visível que elas começam a perceber que é possível integrar o Ensino de Ciências a outras áreas, deixando de lado a visão fragmentada do ensino e seus componentes curriculares.

O formato escolhido para os encontros, nos quais se adotou uma discussão inicial sobre as atividades de sala, uma proposição para elas discutirem e a escolha do próximo tema ao final, agradou muito às professoras e trouxe excelentes resultados:

A questão de não trabalhar o Ensino de Ciências de forma estanque, de forma isolada, mas de forma interdisciplinar e não só na educação infantil, mas no primeiro ano, no segundo, enfim, em todos os segmentos (Professora B).

No caso, eu utilizei o projetinho do meio ambiente que era para trabalharmos, e eu fiz apresentações do que foi falado nas coordenações da parte que você entregou para a gente e foi muito bom (Professora F).

O tema da água que você colocou eu adaptei à abordagem para o conteúdo do Corpo Humano, bem como para a idade deles, e eles se interessaram, eles participaram da aula, comentaram e eu acredito que houve aprendizagem por causa dos temas que têm a ver com essa adaptação que a gente fez para a idade deles (Professora C).

Foi perceptível o avanço nos trabalhos realizados na sala com os alunos, além de uma nova percepção da importância do Ensino de Ciências, reconhecendo que há o conhecimento das Ciências em tudo e que, diferente do que imaginavam, o fazer Ciências em sala de aula depende de um novo olhar e enfoque dado pelos professores. Agora elas perceberam que os alunos carregam consigo conhecimentos prévios e que o papel do docente será mediar o que já eles já possuem com o novo que irão ensinar.

\section{Reflexos das atividades formativas}

A fala da professora $\mathrm{F}$ representa bem o impacto dos encontros de formação:

Aquele projetinho que você deu e que tem um monte de coisa para se trabalhar do meio ambiente e foi muito interessante porque os meninos gostaram bastante, porque principalmente quando você leva para a prática fica mais gostoso até de se trabalhar e você vê o entusiasmo deles, e quando é só aquela coisa de teoria eles não se interessam muito (Professora F). 
Após cada encontro, ao andar pelos corredores da escola era possível notar os desdobramentos das atividades realizadas com as professoras. As aulas realizadas após o encontro sobre a temática Água resultaram em atividades para alunos do 1ㅇ, 20 e 50 anos (Figura 1), lembrando que essa temática foi abordada no 20 encontro com as professoras (Quadro1). Para cada ano as professoras realizaram adaptações para as características e necessidades de cada turma, relacionando os conteúdos de Ciências ao Português por meio do registro, leitura, desenho e criação de histórias em quadrinhos e até mesmo um experimento sobre banho sustentável.

Figura 1 - Imagens das Atividades Sobre o Tema Água Desenvolvido Pelas Professoras Junto com os Alunos
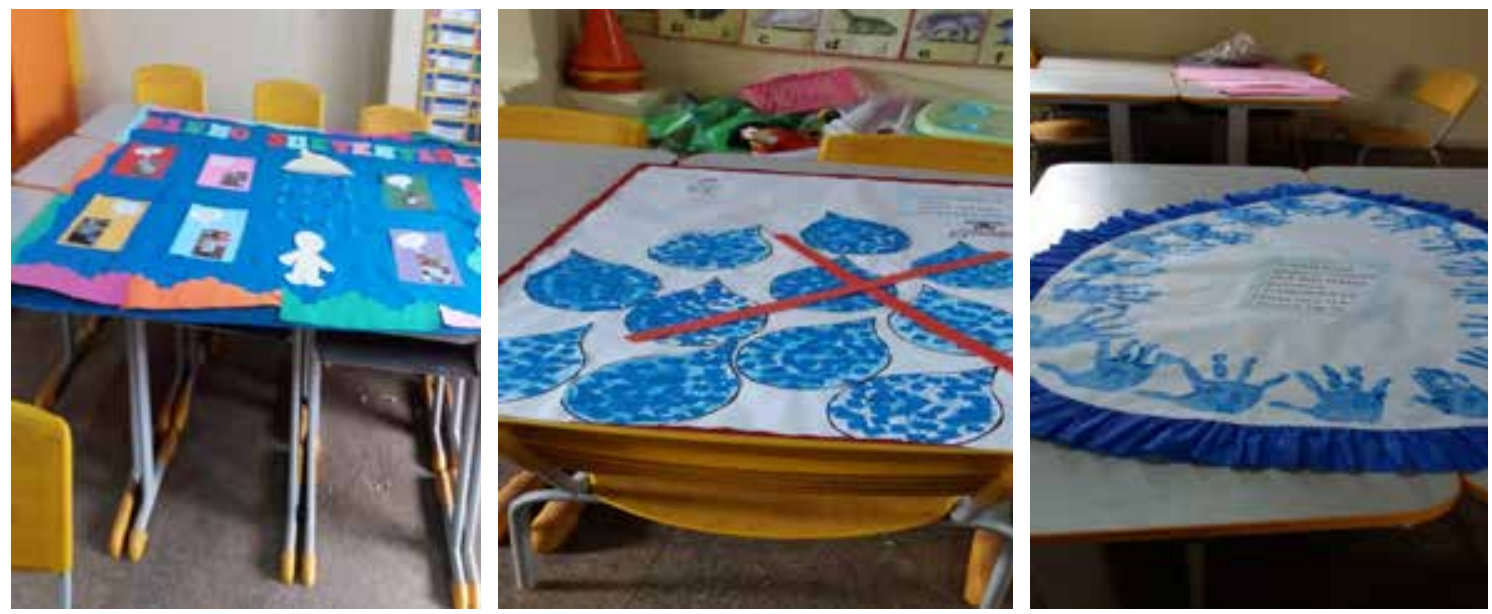

* Nas três imagens os alunos abordam o uso racional da água, como o banho sustentável e os cuidados com desperdício.

Da mesma forma, após as temáticas sobre Alimentação e Meio Ambiente encontrávamos atividades de Ciências por toda a escola. Produções textuais, registros no quadro, murais com quadrinhos e objetos construídos pelos alunos a partir de materiais eram encontrados nos arredores da escola (Figura 2). 
Figura 2 - Exemplos de produções dos alunos a partir das aulas de ciências
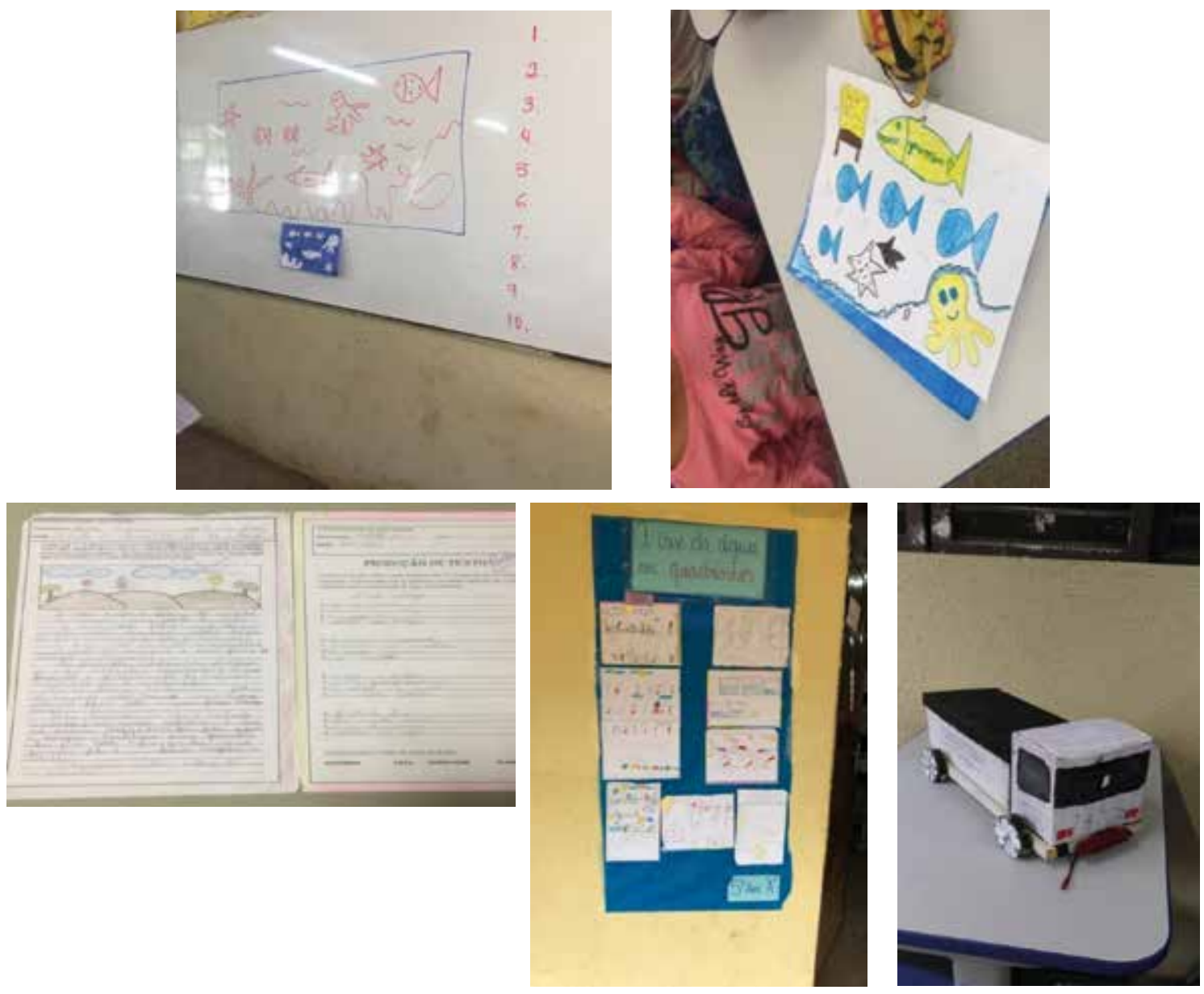

* As primeiras duas imagens são de esquemas/desenhos que os alunos fizeram sobre os seres vivos que vivem e dependem da água. As duas imagens seguintes retratam produções textuais sobre o uso da água. A última imagem é um exemplo do trabalho com materiais recicláveis feitos pelos alunos.

Diante dos relatos e registros apresentados é notável a importância dada aos conteúdos de Ciências pelas professoras e alunos/as da escola. Viveiro e Zancul (2013, p. 4), nesse sentido, afirmam que ao se trabalhar na formação de professores as concepções, conceitos e possibilidades teórico-metodológicas contribuem para a valorização e enriquecimento do ensino de Ciências por parte dos professores na sala de aula. Além disso, o ensino de Ciências na perspectiva de alfabetização científica é considerado uma estratégia para a formação de um cidadão capaz de se mover numa sociedade especialmente marcada e rodeada pelo avanço do conhecimento científico e suas novas tecnologias (CARVALHO; RAMALHO, 2018).

Nesse sentindo, a figura do professor assume um papel importante na organização da didática dos conteúdos em sala de aula, incentivando o espírito investigativo e o confronto de ideias (VIECHENESKI; CARLETTO, 2016). Para que o professor, no entanto, possa desempenhar esse papel, ao longo do seu processo formativo, a investigação ou a pesquisa devem estar presentes como princípio formador (BYBEE, 2000), pois quando este é ausente o professor mostra dificuldade em Ensinar ciências numa perspectiva investigativa (GODOY; SEGRRA; MAURO, 2014; SANTANA, FRANZOLIN, 2018). 
Sendo assim, trabalhar o ensino de Ciências nos Anos Iniciais é de suma importância, pois as crianças carregam consigo suas curiosidades, seus conhecimentos prévios e as dúvidas que são desencadeadas no momento em que começam a criar possibilidades para resolver determinados problemas, mostrando-se fundamental que os professores levem em consideração a curiosidade da criança pelo ambiente em que vive (GOLDSCHMIDT, 2012).

\section{CONSIDERAÇÕES FINAIS}

A partir dos resultados apresentados podemos constatar que as atividades realizadas nas Coordenações Pedagógicas da escola em questão proporcionaram às professoras e à pesquisadora excelentes momentos de aprendizagem e reflexão sobre a própria prática docente, possibilitando inserir os conteúdos de Ciências nos planejamentos. As aulas realizadas após os encontros de formação incorporaram não só as temáticas trabalhadas, mas também estratégias discutidas com as professoras.

A Coordenação Pedagógica é um ambiente rico e deve ser valorizado como espaço de troca de vivências e experiências dos professores, permitindo que estes repensem seu papel no ensino e formação de seus estudantes.

A participação ativa das docentes em todas as atividades reforça a ideia de que as demandas, quando partem do grupo e são organizadas pelo grupo, ganham uma outra dimensão. $\mathrm{O}$ caráter colaborativo desse grupo garante uma cumplicidade diante do desafio de ensinar na perspectiva de um ensino mais investigativo, relacionando e integrando as Ciências no contexto de outras disciplinas.

Ainda nessa perspectiva, é importante ressaltar que foi essencial a pesquisadora/ coordenadora ser professora regente da escola, pois os laços de confiança estabelecidos com as demais docentes foram de grande valia para o desenvolvimento das práticas pedagógicas em sala de aula, bem como as discussões em torno dos temas trabalhados nas Coordenações Pedagógicas. Fazer parte do grupo da escola trouxe bons resultados, possibilitando que as professoras questionassem e chamassem em outros momentos fora da coordenação para compartilhar o que estavam colocando em prática com seus alunos, solucionando suas dúvidas. Com um diálogo aberto as professoras envolvidas sentiam-se confiantes e comprometidas a ajudarem e serem ajudadas.

Isso posto, investir na formação continuada de professores dos Anos Iniciais em Ciências é fundamental, e para isso outras ações importantes seriam a constituição e o fortalecimento de grupos de formação nas próprias escolas e o incentivo na formação de professores para assumirem o papel de coordenadores nesses grupos. A formação de formadores, especificamente nos Anos Iniciais para conhecimento específico ainda é um tema que precisa ser aprofundado no contexto de formação de professores.

\section{REFERÊNCIAS}

ALARCÃO, I. Formação reflexiva de professores: estratégias de supervisão. Portugal: Porto Editora, 1996.

ALARCÃO, I. Professores reflexivos em uma escola reflexiva. 8. ed. São Paulo: Cortez, 2011.

ANDERSON, R. D. Inquiry as an organizing them for science curricula. In: ABELL, S. K.; LEDERMAN, N. G. Handboock of research on science education. New York Routledge, 2007. p. 808-830

BARDIN, L. Análise de conteúdo. Lisboa: Edições 70, 2011. 
BASTOS, D. G. A coordenação pedagógica coletiva: limites e possibilidades. 2014. Monografia (Especialização em Coordenação Pedagógica) - Universidade de Brasília, Centro de Estudos Avançados, Brasília, 2014.

BAUER, M.W.; GASKELL, G. Pesquisa qualitativa com texto, imagem e som. Um manual prático. 2. ed. Editora: Vozes. Petrópolis RJ, 2002.

BIZZO, N. M. V. Ciências: fácil ou difícil? São Paulo: Ática, 1998.

BRASIL. Base Nacional Comum Curricular. Brasília: MEC; SEB, 2017.

BRASIL. Parâmetros Curriculares Nacionais: introdução aos Parâmetros Curriculares Nacionais. Brasília: MEC/SEB, 1997.

BRASIL. Lei de Diretrizes e Bases da Educação Nacional. 1996. Disponível em: http://www.planalto.gov.br/ ccivil_03/leis/19394.htm

BRASIL. CNE. Resolução CNE/CP n. 1, de 15 de maio de 2006.

BYBEE, R. W. Teaching science as inquiry. In: MINSTRELL, J.; VAN ZEE, E. Inquiring into inquiry learning and teaching in science. Washington: American Association for the Advancement of Science, 2000. p. 21-46.

CARVALHO, A. M. P. O ensino de Ciências e a proposição de sequências de ensino investigativas. In: CARVALHO, A. M. P. (org.). Ensino de ciências por investigação - condições para implementação em sala de aula. São Paulo: Cengage Learning, 2013.

CARVALHO, C. S. C.; RAMALHO, B. L. O ensino das ciências da natureza nos anos iniciais da escolarização básica: das necessidades formativas à profissionalização docente. Revista Entreideias: Educação, Cultura e Sociedade, v. 7, n. esp, p. 107-126, 2018.

COLOMBO JUNIOR, P. D.; LOURENÇO, A. B.; SASSERON, L. H.; CARVALHO, A. M. P. Ensino de física nos anos iniciais: análise da argumentação na resolução de uma "atividade de conhecimento físico". Investigações em Ensino de Ciências, v. 17, n. 2, p. 489-507, 2012.

CRESPO, S. Elementary Teacher Talk in Mathematics Study Groups. Educational Studies in Mathematics, v. 63, n. 1, p. 29-56, 2006.

DARLING-HAMMOND, L.; WEI, R. C.; ANDREE, A.; RICHARDSON, N.; ORPHANOS, S. Professional Learning in the Learning Profession: A Status Report on Teacher Development in the United States and Abroad. Washington DC: National Staff Development Council, 2009.

DISTRITO FEDERAL. Secretaria de Educação. Currículo em Movimento da Educação Básica Distrito Federal. Livro 1. Versão para validação, 2013.

FERNANDES, R. C. A. Educação continuada de professores no espaço - tempo da coordenação pedagógica: avanços e tensões, 2007. Dissertação (Mestrado em Educação) - Universidade de Brasília, Faculdade de Educação, Brasília, 2007.

FRANCO, M. J. do Nascimento; GONÇALVES, L. S. M. Coordenação pedagógica e formação de professores: caminhos de emancipação ou dependência profissional. Psicologia da Educação, v. 37, p. 63-71, 2013.

GABINI, W. S.; DINIZ, R. E. S. A formação continuada, o uso do computador e as aulas de ciências nos anos iniciais do Ensino Fundamental. Ensaio: Pesquisa em Educação em Ciências, v. 14, n. 3, p. 333-348, 2012.

GARCÍA, A. E.; MARCELO, C. Los grupos de trabajo de los profesores como actividad autoformativa para crear una cultura colaborativa. Tendencias Pedagógicas, n. 2, p. 219-234, 1998.

GIL, A. C. Métodos e técnicas de pesquisa social. 6. ed. São Paulo: Ed. Atlas, 2008.

GODOY, A. V.; SEGRRA, C. I.; MAURO, M. F. Una experiencia de formación docente en el área de Ciencias Naturales basada en la indagación escolar. Revista Eureka, v. 11, n. 3, p. 381-397, 2014.

GOLDSCHMIDT, A. I. O ensino de ciências nos anos iniciais: sinalizando possibilidades de mudanças. 2012. Tese (Doutorado) - Universidade Federal de Santa Maria, Santa Maria, 2012.

IMBERNÓN, F. Formação continuada de professores. Porto Alegre: Artmed, 2010.

JOHNSON, S. M. How Best to Add Value? Strike a balance between the individual and the organization in school reform. Epi Briefing Paper, v. 249, p 1- 6, 2009.

KRASILCHIK, M.; MARANDINO, Martha. Ensino de ciências e cidadania. São Paulo: Moderna, 2004.

LAVILLE, C.; DIONNE, J. A construção do saber: manual de metodologia da pesquisa em ciências humanas. Porto Alegre: Artmed, 1999.

LIMA, M. E. C. C.; MAUÉS, E. Uma releitura do papel da professora das séries iniciais no desenvolvimento e aprendizagem de ciências das crianças. Ensaio: Pesquisa em Educação em Ciências, v. 8, n. 2, 2006.

LIMA, P. G.; SANTOS, S. M. O coordenador pedagógico na educação básica: desafios e perspectivas. Educere et Educare, v. 2, n. 4, p. 77-90, 2007. 
LUDKE, M.; ANDRÉ, M. E. D. A. Pesquisa em educação: abordagens qualitativas. 2. ed. Rio de Janeiro: EPU, 2017.

MALDANER, O. A. A formação inicial e continuada de professores de química: professores/pesquisadores. 3. ed. Ijuí: Editora Unijuí, 2006.

MUNFORD, D.; LIMA, M. E. C. C. Ensinar ciências por investigação: em quê estamos de acordo. Ensaio: Pesquisa em Educação em Ciências, v. 9, n. 1, p. 89-111, 2007.

NÓVOA, A. (org.). Vidas de professores. 2. ed. Porto: Porto Editora, 2007.

NÓVOA, A. Os professores e sua formação. Lisboa: Dom Quixote, 1992.

PIMENTA, S. G.; FUSARI, J. C.; PEDROSO, C. C. A.; PINTO, U. A. Os cursos de licenciatura em pedagogia: fragilidades na formação inicial do professor polivalente. Educação e Pesquisa, v. 43, n. 1, p. 15-30, 2017.

POPP, J. S.; GOLDMAN, S. R. Knowledge building in teacher professional learning communities: focus and meeting matters. Teaching and Teacher Education, v. 59, p. 346-359, 2016.

PORTO, Y. S. Formação continuada: a prática pedagógica recorrente. Campinas: Papirus, 2000. p. 11-37.

RONFELDT, M.; FARMER, S. O.; MCQUEEN, K.; GRISSOM, J. A. Teacher Collaboration in Instructional Teams and Student Achievement. American Educational Research Journal, v. 52, n. 3, p. 475-514. 2015.

SANTANA, R. S.; FRANZOLIN, F. O ensino de ciências por investigação e os desafios da implementação na práxis dos professores. REnCiMa, v. 9, n. 3, p. 218-237, 2018.

SASSERON, L. H. Alfabetização científica no Ensino Fundamental: estrutura e indicadores deste processo em sala de aula. 2008. 180f. Tese (Doutorado em Ensino de Ciências e Matemática) - Universidade de São Paulo, Faculdade de Educação, São Paulo, 2008.

SASSERON, L. H.; CARVALHO, A. M. P. Alfabetização científica: uma revisão bibliográfica. Investigação em Ensino de Ciências, v. 16, n. 1, p. 59-7, 2011.

SCHNETZLER, R. P. A investigação-ação na formação continuada de professores de ciências. Ciência \& Educação, v. 9, n. 1, p. 27-39, 2003.

$\mathrm{SCHÖN,} \mathrm{A.} \mathrm{D.} \mathrm{Formar} \mathrm{professores} \mathrm{como} \mathrm{profissionais} \mathrm{reflexivos.} \mathrm{In:} \mathrm{NÓVOA,} \mathrm{A.} \mathrm{(coord.).} \mathrm{Os} \mathrm{professores} \mathrm{e}$ sua formação. Lisboa: Dom Quixote, 1992. p. 77-92.

SILVA, E. F. A coordenação pedagógica como espaço de organização do trabalho escolar: o que temos e o que queremos. Quem sabe faz a hora de construir o projeto político-pedagógico. Campinas: Papirus, 2007.

SILVA, K. C. D. A formação no curso de Pedagogia para o ensino de ciências nas séries iniciais. 2005. Dissertação (Mestrado em Educação - Área de Concentração: Ensino na Educação Brasileira) - Universidade Estadual Paulista "Júlio de Mesquita Filho", Faculdade de Filosofia e Ciências, Marília, SP, 2005.

STOSICH, L. S. Building teacher and school capacity to teach to ambitious standards in high-poverty schools. Teaching and Teacher Education, v. 58, p. 43-53, 2016.

TARDIF, M. Saberes docentes e formação profissional. 10. ed. Petrópolis: Vozes, 2014.

TRIPP, D. Action research: a methodological introduction. Educação e Pesquisa, v. 31, n. 3, p. 443-466, 2005.

TRIVELATO, S. L. F.; TONIDANDEL, S. M. R. Ensino por investigação: eixos organizadores para sequências de ensino de Biologia. Ensaio: Pesquisa em Educação em Ciências, v. 17, p. 97-114, 2015.

VASCONCELLOS, C. S. Coordenação do trabalho pedagógico: do projeto político-pedagógico ao cotidiano da sala de aula. São Paulo: Libertad Editora, 2004.

VIECHENESKI, J. P.; CARLETTO, M. R. Iniciação à alfabetização científica nos anos iniciais: contribuições de uma sequência didática. Investigações em Ensino de Ciências, v. 18, n. 3, p. 525-543, 2016.

VIVEIRO, A. A.; ZANCUL, M. C. S. A formação de professores para o ensino de ciências nos anos iniciais da escolarização. Enseñanza de las Ciencias, n. Extra, p. 3.732-3.736, 2013.

ZEICHNER, K. M. A. Formação reflexiva de professores: ideias e práticas. Lisboa: Educa, 1993.

ZÔMPERO, A. F.; LABURÚ, C. E. Atividades investigativas no ensino de Ciências: Aspectos históricos e diferentes abordagens. Ensaio: Pesquisa em Educação em Ciências, v. 13, n. 3, p. 67-80, 2011. 